\title{
Anti-Inflammatory Effect of Bifidobacterium longum on Macrophage-Like THP-1 Cells via Epithelial Cell Caco-2
}

\author{
Reina TAKISAWA ${ }^{1}$, Yousuke NishitanI ${ }^{2}$, Masashi MIzUnO2,3 and Ro OSAWA ${ }^{1,2 *}$ \\ ${ }^{1}$ Department of Bioresource Science, Graduate School of Agricultural Science, Kobe University, Rokko-dai 1-1, Nada-ku, \\ Kobe 657-8501, Japan \\ 2 Health Bioscience Team, Organization of Advanced Science and Technology, Kobe University, Rokko-dai 1-1, Nada-ku, \\ Kobe 657-8501, Japan \\ 3 Department of Agrobioscience, Graduate School of Agricultural Science, Kobe University, Rokko-dai 1-1, Nada-ku, Kobe \\ 657-8501, Japan
}

Received January 19, 2009; Accepted February 26, 2009

\begin{abstract}
We examined the immunomodulation capability of Bifidobacterium longum strains via a Transwell co-culture system using human colonic epithelial cells, Caco-2, in the upper chamber, and human macrophage-like cells, THP1, in the lower chamber of the culture. Heat-treated cells of three B. longum strains, JCM1217' ${ }^{\mathrm{T}}$, KT237 or H7-115, were added to the upper chamber to allow direct contact with Caco-2 cells and the culture was incubated for $24 \mathrm{hr}$. After incubation, THP-1 cells in the lower chamber were placed in a separate well containing fresh medium with LPS and incubated for 6 hr. After incubation, we found that TNF- $\alpha$ secretion from THP-1 cells, that had been co-cultured with Caco-2 directly contacting heat-treated cells of B. longum strains, especially H7-115, was suppressed. This was, however, not the case in an the almost identical experiment using B. longum cells killed under ultra-violet light (not heat-treated). We then blocked Caco-2 TLR2 with anti-TLR 2 antibodies in another co-culture experiment and found that blocking TLR2 canceled the indirect anti-inflammatory effect of $B$. longum H7-115. The evidence suggests that some heat-resistant somatic structures of $B$. longum can modulate a host's immune response at least via TLR2 expressed on intestinal epithelial cells.
\end{abstract}

Key words: Bifidobacterium longum; immunomodulation; co-culture system; TLR2

The genus Bifidobacterium is the most predominant members of the human intestinal microflora. It has long been suggested that Bifidobacterium species have important roles in maintaining or promoting general health, preventing infection by enteric pathogens, suppressing the growth of other members of intestinal microflora that might produce cancer-causing substances, and modulating the host immune system in humans $(2,13)$. Bifidobacterial cultures have thus been increasingly used as probiotics in pharmaceuticals and foods $(6,10)$, and strains belonging to $B$. longum, $B$. breve, and $B$. bifidum have been intensively employed as probiotic bifidobacteria to date $(1,3)$.

The immunomodulatory properties of bifidobacterial strains have been described in a number of studies. For example, He et al. (4) reported that a cultured murine macrophage-like cell line produced a range of cytokines in the presence of different species of heat-inactivated bifidobacteria. More recently, Medina et al. (7)

\footnotetext{
*Corresponding author. Mailing address: Department of Bioresource Science, Graduate School of Agricultural Science, Kobe University, Rokko-dai 1-1, Nada-ku, Kobe 657-8501, Japan. Phone \& Fax: +81-78-803-5804. E-mail: tamie@opal.kobe-u.ac.jp
}

demonstrated that different strains of Bifidobacterium longum had different abilities to induce cytokine production in human peripheral blood mononuclear cells, suggesting that immunomodulation by bifidobacteria present in the human host intestine varies not only at the species level but also at the strain level. It should be noted, however, that most of these findings were based on in vitro experiments, in which some antigen-presenting cells (i.e., macrophages, dendritic cells) were in direct contact with bifidobacterial cells. Such direct contact of commensal bacteria and antigenpresenting cells (APCs) may be less likely in vivo except for specialized epithelial cells (M cells), since they are usually separated by host intestinal epithelial cells (ECs). Using an in vitro co-culture system, however, Rimoldi et al. (9) reported that dendritic cells underneath ECs could be activated by inflammatory mediators released from ECs stimulated by direct contact with commensal bacteria. This points to the possibility of EC-mediated activation of the host immune system by bifidobacteria. In this context, we here describe indirect and strainspecific immunomodulation of Bifidobacterium longum in a novel in vitro co-culture system using human ECs (Caco-2) and APCs (THP-1). 
In the present study, we used $3 B$. longum strains, JCM1217 ${ }^{\mathrm{T}}$ purchased from the Japanese Collection of Microorganisms, KT237 isolated from yogurt, and H7115 isolated from adult feces. The strains were incubated anaerobically in an Anaero pack (Mitsubishi Gas Chemical Co., Inc., Tokyo, Japan) at $37^{\circ} \mathrm{C}$ for $24 \mathrm{hr}$ in MRS broth (Oxoid Ltd., Basingstoke, Hampshire, UK) supplemented with $0.5 \%$ L-cysteine (Wako Pure Chemical Industries, Ltd., Osaka, Japan). The bacteria were harvested by centrifugation, washed three times with sterile phosphate-buffered saline (PBS; $\mathrm{pH}$ 7.4) and resuspended in PBS. Bacterial cells were then either killed under ultraviolet light (UV-killed) or heat-treated at $100^{\circ} \mathrm{C}$ for $30 \mathrm{~min}$, washed three times with sterile PBS, and re-suspended in PBS at a final cell concentration of ca. $10^{8} / \mathrm{ml}$ as measured by direct microscopic counting. The bacterial suspension thus prepared was used for subsequent experiments.

The monocytic cell line THP-1 was purchased from the American Type Culture Collection. THP-1 cells were maintained in RPMI1640 (Invitrogen, Tokyo, Japan) supplemented with 10\% FBS (Biological Industries, Beit, Israel), $100 \mathrm{U} / \mathrm{ml}$ penicillin and $100 \mu \mathrm{g} / \mathrm{ml}$ streptomycin at $37^{\circ} \mathrm{C}$ under a humidified $5 \% \mathrm{CO}_{2}$ atmosphere. THP- 1 cells for co-culture experiments were differentiated to macrophage-like cells at a density of $1.0 \times 10^{5}$ cells $/ \mathrm{ml}$ by treatment with $162 \mathrm{nM}$ phorbol myristate acetate (Sigma, St. Louis, MO, USA) for $72 \mathrm{hr}$ and quiescence in complete RMPI1640 medium for $24 \mathrm{hr}$ before the co-culture experiments.

A co-culture system was established essentially following the methodology described by Tanoue et al. (14). Briefly, a human intestinal epithelial cell line Caco2 cells was maintained in Dulbecco's modified Eagle's minimal essential medium (glutamine, high glucose, Sigma) supplemented with $1 \%$ non-essential amino acids (Sigma), 10\% FBS (Biological Industries), $100 \mathrm{U} / \mathrm{ml}$ penicillin and $100 \mu \mathrm{g} / \mathrm{ml}$ streptomycin at $37^{\circ} \mathrm{C}$ under a humidified of $5 \% \mathrm{CO}_{2}$ atmosphere. The cells were incubated at $37^{\circ} \mathrm{C}$ under a humidified $5 \% \mathrm{CO}_{2}$ atomosphere. Caco-2 cells used for the co-culture experiments were seeded in the upper chamber of a Transwell filter (Corning CoStar Corp., Cambridge, USA) for 3 weeks (48-60 passages) until transepithelial resistance (TER) of $100 \mathrm{ohm} / \mathrm{cm}^{2}$ was observed. The upper chamber Caco-2 cells were then placed in the lower chamber of the Transwell preloaded with THP-1 cells and incubated for $24 \mathrm{hr}$ in complete RPMI1640 (Fig. 1). After incubation, all media were replaced with RPMI1640 and $1.0 \times 10^{8}$ cells of heat-treated or UVkilled $B$. longum strains were applied to the apical side of

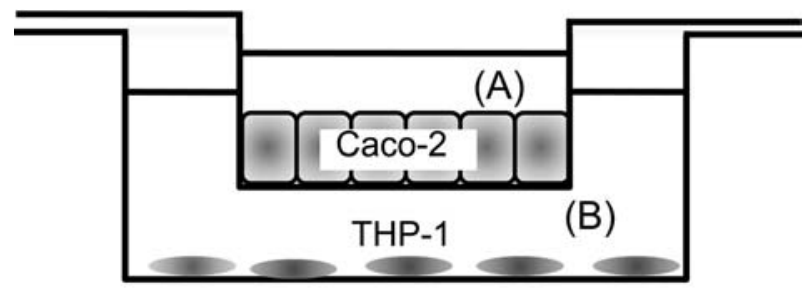

Fig. 1. Schematic drawing of a Transwell co-culture system. Caco-2 cells form a continuous monolayer epithelium on a microporous filter, which constitutes the bottom of the Transwell insert. The monolayer of Caco-2 cells is continuous and thus separates the chamber into an upper chamber (A) and a lower chamber (B) containing THP-1 cells at the bottom of well.

the Caco-2 cell layer in the upper chamber and further incubated at $37^{\circ} \mathrm{C}$ under a humidified $5 \% \mathrm{CO}_{2}$ atmosphere for $24 \mathrm{hr}$. During incubation, the TER value of the upper chamber filter was periodically measured by a Millicell-ERS instrument (Millipore, Eschborn, Germany) and there was no marked decrease in the TER value, indicating that the Caco- 2 cell layers were intact throughout the experiments.

After incubation, TNF- $\alpha$ concentrations in the culture supernatants of the lower chamber were quantified with a cytotoxicity assay with L929 cells (actinomycin Dtreated murine fibroblast cell line) using human rTNF- $\alpha$ (Wako) as the standard, as described by Takada et al. (11). Concentrations of IL-10, TGF- $\beta 1$ and PGE2 in culture supernatants of the lower chamber were also measured by commercially available ELISA kits (Invitrogen for IL-10, and R\&D Systems, Minneapolis, USA for TGF- $\beta 1$ and PGE2). The assay results showed no significant production of either Caco-2 cells or THP-1 cells in the lower chamber regardless of the presence of bifidobacterial cells in the upper chamber (data not shown).

Subsequently, THP-1 cells were then placed in wells containing complete RPMI1640 with LPS (LPS from Escherichia coli O26:B6, Sigma) at a concentration of $100 \mathrm{ng} / \mathrm{ml}$ and incubated at $37^{\circ} \mathrm{C}$ in a humidified $5 \% \mathrm{CO}_{2}$ atmosphere for $6 \mathrm{hr}$. After incubation, culture supernatants were measured for TNF- $\alpha$ concentrations using the cytotoxicity assay described above. The assay results showed that there was no significant LPS-induced TNF- $\alpha$ secretion by the THP- 1 cells that had been cocultured with Caco2 cells in direct contact with the UVkilled bifidobacteria (data not shown), while the TNF- $\alpha$ secretion was significantly suppressed in the THP-1 cells that had been co-cultured with Caco2 cells in direct contact with the heat-treated cells of B. longum H7-115 


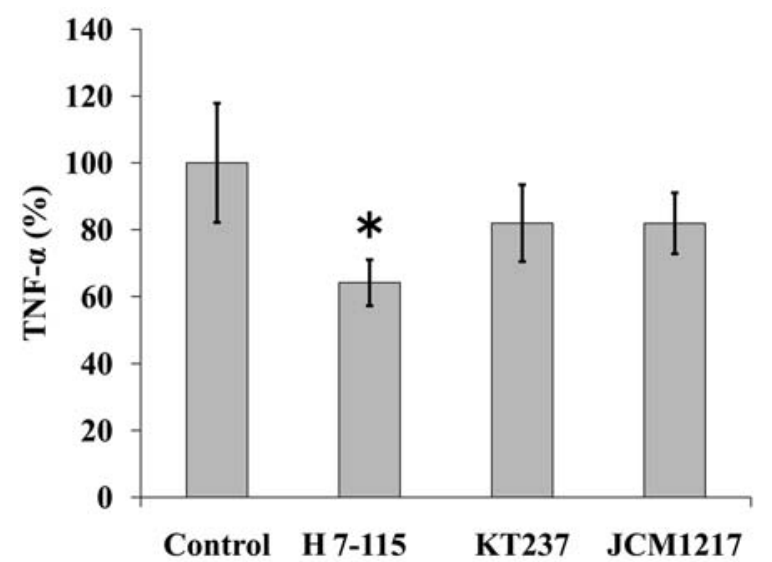

Fig. 2. TNF- $\alpha$ production by THP-1 after LPS (100 ng/ml) stimulation after indirect co-culturing with $B$. longum strains. ${ }^{*} p<0.05$ compared with control.

(Fig. 2). This result suggests that some heat-resistant somatic structures of $B$. longum triggered Caco- 2 cells to produce some substances immunosuppressive for THP-1 cells that have yet to be identified. Kumar et al. (5) reported epithelial cells in contact with enteric commensal bacteria generate reactive oxygen species (ROS) accounting for blockade of the NF-кB pathway. ROS may be involved in the immunosuppressive effect observed in this study.

The above results encouraged us to determine how Caco-2 cells recognized B. longum H7-115. Since TLR2 is known to play an important role for host cells, including ECs, in recognizing Gram-positive bacterial lipopeptide and peptidoglycan (12), we prepared another set of the Transwell co-culture, in which Caco-2 cells in the upper chamber were incubated in complete RMPI1640 medium containing $10 \mu \mathrm{g} / \mathrm{ml}$ TLR2 antibody (Cosmo Bio Co., Ltd., Tokyo, Japan) or a control antibody (Sigma) for $1 \mathrm{hr}$ at $37^{\circ} \mathrm{C}$ in a humidified 5\% $\mathrm{CO}_{2}$ atmosphere before the heat-treated cell preparation of $B$. longum H7-115 was applied to the chamber. Cocultures were then incubated for $24 \mathrm{hr}$ at $37^{\circ} \mathrm{C}$ in a humidified $5 \% \mathrm{CO}_{2}$ atmosphere. After incubation, THP1 cells in the lower chambers were placed in wells containing complete RPMI1640 with LPS (Sigma) at a concentration of $100 \mathrm{ng} / \mathrm{ml}$ and incubated at $37^{\circ} \mathrm{C}$ in a humidified $5 \% \mathrm{CO}_{2}$ atmosphere for $6 \mathrm{hr}$. After incubation, the culture supernatants were measured for TNF- $\alpha$ concentrations using the cytotoxicity assay as described above and we found that such blocking TLR2 of Caco-2 cells before direct contact with $B$. longum H7115 cells abolished the suppression of TNF- $\alpha$ production by THP-1 cells upon LPS stimulation (Fig. 3). This

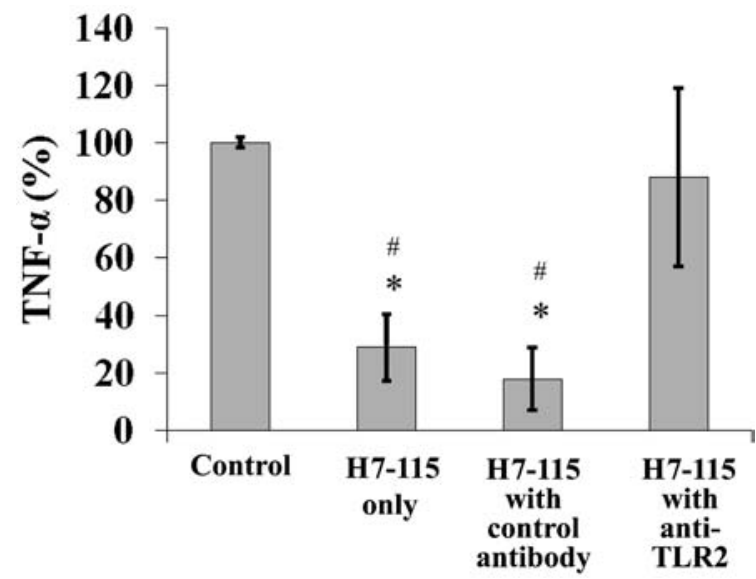

Fig. 3. Effect of TLR2 neutralization of Caco-2 on TNF- $\alpha$ production by THP- 1 after LPS $(100 \mathrm{ng} / \mathrm{ml})$ stimulation after indirect co-culturing with $B$. longum H7-155. ${ }^{*} p<0.001$ compared with control. ${ }^{*} p<0.05$ compared with antiTLR2.

suggests that $B$. longum $\mathrm{H} 7-115$ cells can induce an immunosuppressive effect via TLR2 of EC and TLR2 of EC might be involved in the immunotolerance. Moreillon and Majcherczy (8) described that innate immunity via TLR2 can be used to detect very subtle differences in Gram-positive walls; thus, the present results suggest that $B$. longum has strain-specific cellsurface structures which are differentially recognized by TLR2 of host ECs. This in turn suggests that the immunomodulatory effects of probiotic $B$. longum on human hosts vary from strain to strain. Further studies are in progress to evaluate these possibilities.

This study was supported by Special Coordination Funds for Promoting Science and Technology, Creation of Innovation Centers for Advanced Interdisciplinary Research Areas (Innovative Bioproduction Kobe), MEXT, Japan.

\section{REFERENCES}

(1) Arunachalam KD. 1999. Role of bifidobacteria in nutrition, medicine and technology. Nutr Res 19: 1559-1597.

(2) Ballongue J. 1998. Bifidobacteria and probiotic action. In Lactic Acid Bacteria, Microbiology and Functional Aspects, 2nd ed., Salminen S, von Wright A (eds), Marcel Dekkers Inc., New York, pp 519-587.

(3) Gomes AMP, Malcaata FX. 1999. Bifidobacterium spp. and Lactobacillus acidophilus: biological, biochemical, technological and therapeutical properties relevant for use as probiotics. Trends Food Sci Technol 10: 139-157.

(4) He F, Morita H, Ouwehand AC, Hosoda M, Hiramatsu 
M, Kurisaki J, Isolauri E, Benno Y, Salminen S. 2002. Stimulation of the secretion of pro-inflammatory cytokines by Bifidobacterium strains. Microbiol Immunol 46: 781-785.

(5) Kumar A, Wu H, Collier-Hyams LS, Hansen JM, Li T, Yamoah K, Pan ZQ, Jones DP, Neish AS. 2007. Commensal bacteria modulate cullin-dependent signaling via generation of reactive oxygen species. EMBO J 26: 4457-4466.

(6) Leahy SC, Higgins DG, Fitzgerald GF, van Sinderen D. 2005. Getting better with bifidobacteria. J Appl Microbiol 98: 1303-1315.

(7) Medina M, Izquierdo E, Ennahar S, Sanz Y. 2007. Differential immunomodulatory properties of Bifidobacterium logum strains: relevance to probiotic selection and clinical applications. Clin Exp Immunol 150: 531-538.

(8) Moreillon P, Majcherczyk PA. 2003. Proinflammatory activity of cell-wall constituents from gram-positive bacteria. Scand J Infect Dis 35: 632-641.

(9) Rimoldi M, Chieppa M, Larghi P, Vulcano M, Allavena P, Rescigno M. 2005. Monocyte-derived dendritic cells activated by bacteria or by bacteriastimulated epithelial cells are functionally different. Blood 106: 2818-2826.

(10) Salminen SJ, Gueimonde M, Isolauri E. 2005. Probiotics that modify disease risk. J Nutr 135: 1294 1298.

(11) Takada K, Ohno N, Yadomae T. 1994. Binding of lysozyme to lipopolysaccharide suppresses tumor necrosis factor production in vivo. Infect Immun 62: 1171-1175.

(12) Takeda K, Akira S. 2004. Microbial recognition by Toll-like receptors. J Dermatol Sci 34: 73-82.

(13) Tanaka R. 1995. Clinical effects of bifidobacteria and lactobacilli. In Probiotics; Prospects of Use in Opportunistic Infection, Fuller R, Heidt PJ, Rusch V, Waaij DVD (eds), Old Herborn University Seminar Monograph 8, Institute for Microbiology and Biochemistry, Herborn-Dill, pp. 141-157.

(14) Tanoue T, Nishitani Y, Kanazaawa K, Hashimoto T, Mizuno M. 2008. In vitro model to estimate gut inflammation using co-cultured Caco-2 and Raw264.7 cells. Biochem Biophy Res Commun 374: 565-569. 